\title{
Health and nutrition education in primary schools in Crete: 10 years' follow-up of serum lipids, physical activity and macronutrient intake
}

\author{
Yannis Manios ${ }^{1}$, Anthony Kafatos ${ }^{2 *}$ and the Preventive Medicine and Nutrition Clinic University of Crete \\ Research Team ${ }^{2}$ \\ ${ }^{1}$ Department of Nutrition \& Dietetics, Harokopio University of Athens, Greece \\ ${ }^{2}$ Preventive Medicine and Nutrition Clinic, School of Medicine, University of Crete, Crete, Greece
}

(Received 1 June 2005 - Revised 4 November 2005 - Accepted 8 November 2005)

\begin{abstract}
The current study is a 4-year follow-up after the 6-year-long health and nutrition intervention programme applied in the primary schools of Crete. The aim of the current work was to identify whether the benefits obtained in certain health indices at the end of the intervention period were also present 4 years later. From a representative population of 441 pupils ( 250 from the intervention schools and 191 from the control schools), biochemical, dietary and physical activity data were obtained at baseline, at the end of the intervention period and after intervention (academic years 1992-1993, 1997-1998 and 2001-2002, respectively). The findings of the current study revealed that the favourable changes in serum lipids observed at the end of the intervention period were maintained from baseline to after intervention for total cholesterol ( -24.3 (SE 1.65) v. -9.70 (SE 2.03) mg/dl; $P=0.001$ ), LDL-cholesterol $(-18.6$ (SE 1.41) v. -2.49 (SE 1.75) $\mathrm{mg} / \mathrm{dl} ; \quad P<0.001)$, HDL-cholesterol ( -8.34 (SE 0.75$) \quad v . \quad-9.60$ (SE 1.10$) \quad \mathrm{mg} / \mathrm{dl} ; \quad P=0.014)$ and total cholesterol: HDL-cholestrol ratio (0.31 (SE 0.06) v. 0.04 (SE 0.05); $P=0.001$ ). Similar favourable changes for the intervention group were observed in leisure-time physical activities (38.3 (SE 11.7) $v$. - 13.2 (SE 10.9) min/week; $P=0.038$ ) and BMI (6.05 (SE $0 \cdot 18) \quad v$. 6.67 (SE 0.21) $\mathrm{kg} / \mathrm{m}^{2}$; $P=0 \cdot 014$ ), whereas no changes were observed in the fitness and dietary indices examined. The findings of the current study are encouraging, indicating maintenance of the favourable changes observed in serum lipids, BMI and physical activity 4 years after the programme had ended.
\end{abstract}

Nutrition education: Children: Diet and physical activity: Serum lipids: Obesity

Over the past 30 years, increased mortality rates from CVD have been observed in the Greek adult population (Kafatos, 1998; Pitsavos et al. 2003). This upward trend is attributed mainly to the dietary and smoking habits, sedentary lifestyle and limited health awareness of contemporary Greeks (Kafatos, 1998; Kafatos et al. 1999). However, both the physiological precursors of CVD, as well as the behavioural patterns related to the development of the disease, have their roots in childhood (Cohen, 2004). Recent data have reaffirmed the link between risk factor exposure in childhood and adolescence, and preclinical atherosclerosis in adulthood (Li et al. 2003; Raitakari et al. 2003). In addition, several longitudinal studies have demonstrated the tracking of certain behaviours related to an increased risk of CVD from childhood to young adulthood (Janz et al. 2000; Boreham et al. 2004; Mikkila et al. 2004).

The beneficial effect of physical activity and diet on cardiovascular health is well recognized. In particular, the risk of CVD mortality or morbidity is inversely related to the level of physical activity (Wei et al. 1999; Lee et al. 2000; Sesso et al. 2000), whereas the adoption of a diet low in saturated fat and rich in olive oil, fruits and vegetables favourably affects certain health indices and reduces the odds of CVD risk (Law, 2000; Pitsavos et al. 2002). These studies raise the importance of an early promotion of healthy dietary patterns and a physically active lifestyle as a potential protective tool for preventing adverse health outcomes in adulthood.

Based on this approach, several school-based health and nutrition education programmes have been implemented worldwide. Although the short-term benefits of the preventive potential of such programmes (Luepker et al. 1996; Harrell et al. 1998; Manios et al. 2002; Hayman et al. 2004) are encouraging, it should not be forgotten that the success of such interventions is best judged in the long term, several years after intervention, in adolescence or adulthood.

To our knowledge, the only school-based study that has conducted a post-intervention follow-up is the Child and Adolescent Trial for Cardiovascular Health (CATCH) study. The intervention applied by the CATCH study was multicomponent, targeting both pupils' behaviour and school environment (i.e. food services and physical education classes). The findings of the follow-up examination 3 years after the programme's cessation revealed a maintenance of the favourable behavioural changes observed during the intervention period, but no changes were observed for the biochemical indices examined (Nader et al. 1999). Regarding the school environment, the favourable changes achieved in the food services and physical education classes during 
the intervention period were also present 4 years after the end of the programme, indicating a long-term effect on institutionalizing these changes into school operation (Kelder et al. 2003; McKenzie et al. 2003; Osganian et al. 2003).

The limited post-intervention data from school-based programmes, as well as the importance of such indices in assessing their long-term effectiveness, has led the Preventive Medicine and Nutrition Clinic to undertake a 10-year follow-up of the Cretan Health and Nutrition Education Programme. In this context, the current study aimed to assess whether the benefits obtained in certain health indices over the 6-year intervention period (Manios et al. 1998a, 1999; Manios \& Kafatos, 1999) were also present 4 years after intervention.

\section{Methods}

The Cretan Health and Nutrition Education programme was initiated in September 1992 with the approval of the Greek Ministry of Education (Manios et al. 1998a, 1999; Manios \& Kafatos, 1999). The population of the intervention group (IG) comprised 4171 children registered in the first grade of primary schools throughout the counties of Iraklio and Rethimno in September 1992, while the 1510 children registered in the county of Hania served as the control group (CG). The total duration of the programme was 6 years, following the same children from the first grade to the sixth grade. The applied intervention programme was based on the health profile component of the 'Know Your Body' school health-promotion programme of the American Health Foundation (Williams et al. 1977; Walter \& Wynder, 1989), which was adapted, modified and supplemented to suit the population studied. A complete and detailed description of the theoretical framework on which the design and implementation of the intervention were based has been provided by Manios et al. (1999) at an interim evaluation of the programme.

A random sample of 24 schools in the intervention counties of Iraklio and Rethimno were selected in order to assess the effectiveness of the programme. Similarly, 16 schools randomly selected in the county of Hania, at which no intervention was delivered, were used as a control group for comparative evaluation purposes. Reflecting the geographical distribution of the population, $49.8 \%$ of these pupils came from urban areas (towns with a population above 40000 ) and $50.2 \%$ came from rural areas (villages with a population less than 4000). Both intervention and control pupils, and their parents, were examined at baseline (academic year 1992-1993) and at the end of the 6-year intervention period (academic year 1997-1998). The final re-examination of both groups took place 4 years after the end of the programme (academic year 2001-2002) and when pupils were in the tenth grade.

The findings presented in the current paper have been based on those pupils participating in all three examinations (i.e. baseline, end of intervention and post-intervention). Parental socio-economic data were obtained at baseline, whereas pupils' anthropometrical, biochemical and behavioural (dietary and physical activity) indices were obtained in all three examinations following the same procedures (Manios et al. 1998a, 1999, 2002).

More specifically, BMI was calculated by dividing weight $(\mathrm{kg})$ by height squared $\left(\mathrm{m}^{2}\right)$. Biochemical indices were assessed using venous blood samples obtained from children early in the morning, after $12 \mathrm{~h}$ overnight fasting. One aliquot of serum was used for the blood analysis of triacylglycerols (TG), total cholesterol
(TC) and HDL-cholesterol (HDL-C) measurements on the same day of collection. LDL-cholesterol (LDL-C) was calculated as follows: $\mathrm{LDL}-\mathrm{C}=\mathrm{TC}+\mathrm{HDL}-\mathrm{C}-(\mathrm{TG} / 5)$ (Friedewald et al. 1972).

Children's dietary intake was obtained from a random sample of $30 \%$ of the baseline cohort by the provision of a weighed record of all foods consumed over a $3 \mathrm{~d}$ period. Thus, complete dietary intake data from all three examinations were obtained for 136 pupils. Furthermore, children's leisure-time physical activity was assessed using a standardized activity questionnaire completed by the parents at baseline and by the pupils themselves at the follow-up examinations. In all cases, the questionnaire was completed in the presence and with the assistance of a member of the research team, assessing any kind of moderate-to-vigorous physical activity (MVPA) of intensity higher than four metabolic equivalents and duration longer than $30 \mathrm{~min}$. More information on the validity and reliability of the questionnaire used are provided elsewhere (Manios et al. 1998b). Cardiorespiratory fitness was assessed with the use of the $20 \mathrm{~m}$ endurance run test (ERT) as described by the EUROFIT Tests Protocol (Committee of Experts on Sports Research, 1988).

Data were reported as means and their standard errors or as medians (25-75th percentiles). The unpaired Student's $t$ test and the non-parametric Mann-Whitney test were used to evaluate any possible differences in baseline measurements for normally and non-normally distributed variables, respectively, between those subjects participating in all three examinations and those who dropped out. General linear mixed model analysis was further used to evaluate the differences between the IG and CG regarding the changes observed in serum lipids, nutrient intake, ERT score and MVPA over the 6-year intervention period and the 10-year follow-up and after controlling for gender, parental educational level, BMI and baseline values. Interschool variation was taken into account by including the random school effect in the model. Furthermore, two stepwise multiple linear regression analyses were carried out in order to assess the parameters related to the changes observed for serum lipids over the 10-year follow-up. The first analysis (model 1) was conducted for 432 subjects, including participation in the intervention programme and the changes observed in BMI and MVPA as independent variables. The second analysis (model 2) was conducted for 132 subjects, including the same independent variables as in model 1 as well as changes in fitness and dietary indices (energy and macronutrient intake). Both analyses were corrected for parental educational level. SPSS 11.0 (SPSS Inc., Texas, USA) software was used to carry out all analyses. The level of statistical significance was set at $P \leq 0.05$.

\section{Results}

Prior to the baseline examination at 1992, parental signed consent forms were obtained for 1046 children. From this cohort, complete baseline anthropometrical, biochemical and parental socioeconomic data were, however, finally obtained from 716 children and their parents. Based on the biochemical data available at the end of the intervention and at the post-intervention examination, the participation rates were $84 \%$ and $61 \%$, respectively. The primary reason explaining drop-outs and losses-to-follow-up was the transition from primary to high school. As the current programme was a school-based one, those children who moved to different locations could not be tracked. 
Table 1 indicates that the average baseline values for most of the variables assessed did not differ significantly between those pupils available after intervention and those who dropped out. The only exception was baseline serum TG concentration, which was significantly higher in those pupils not re-examined at follow-up, compared with those participating in all three examinations (mean 58.7 (SE 2.03) v. mean 52.9 (SE 0.99) $\mathrm{mg} / \mathrm{dl}$; $P=0.004)$.

Table 2 presents the changes in serum lipid levels in the IG and the CG, over the intervention period and at the post-intervention follow-up examination. The differences between the two groups regarding the changes in LDL-C and TC:HDL-C ratio during the 6-year intervention period were in line with those presented in a previous publication (Manios et al. 2002), favouring the IG pupils. Over the 10-year period from baseline to post-intervention follow-up examination, the current study revealed a significantly higher decrease in serum TC and LDL-C concentrations for the IG than the CG pupils (-24.3 (SE 1.65) v. - 9.70 (SE 2.03) mg/ dl, $P=0.001 ;-18.6$ (SE 1.41) v. -2.49 (SE 1.75$) \quad \mathrm{mg} / \mathrm{dl}$, $P<0.001)$. Furthermore, the decrease observed in serum HDL-C concentration was significantly lower for the IG than the CG subjects $(-8.34$ (SE 0.75) v. -9.60 (SE 1.10) $\mathrm{mg} / \mathrm{dl} ; P=0.014)$, whereas the increase in TC:HDL-C ratio was significantly higher for the CG than the IG (0.31 (SE 0.06) v. 0.04 (SE 0.05); $P=0.001$ ).

The results of the stepwise multiple linear regression analysis are summarised in Table 3. As indicated by both regression models (models 1 and 2), participation in the intervention programme significantly accounted for the favourable changes observed in TC, LDL-C and TC: HDL-C ratio. Furthermore, the initial analysis (model 1) revealed that the change observed for BMI was positively associated with the changes in LDL-C,
TC: HDL-C ratio and TG, whereas an inverse relationship was found between the change in leisure-time MVPA and the changes observed for TC, TC: HDL-C ratio and TG. When, however, fitness and dietary indices were included in the analysis (model 2), some of these associations between changes in leisure-time MVPA and BMI with TC, LDL and TG lost their significance. Finally, and as indicated by the second regression model, the change in ERT score was found to be inversely associated with the changes observed in the concentrations of TC and TG. No other significant correlations were observed.

Changes in certain anthropometrical, physical activity and fitness indices are summarised in Table 4. In accordance with previously presented data (Manios et al. 2002), the changes over the 6-year intervention period in BMI, leisure-time MVPA and ERT score were in favour of the IG subjects. Regarding the changes observed over the 10-year period, from baseline to the post-intervention follow-up examination, the increase in BMI was significantly lower for the IG than the CG pupils (6.05 (SE 0.18) v. 6.67 (SE 0.21$) \mathrm{kg} / \mathrm{m}^{2} ; P=0.014$ ), although BMI increased in both groups. Furthermore, the IG pupils significantly increased the time they devoted to MVPA compared with the CG children, in whom a decrease was observed (38.3 (SE 11.7) v. - 13.2 (SE 10.9) $\mathrm{min} /$ week; $P=0.038$ ). The changes in ERT score over the same period did not, however, differentiate significantly between the two groups.

As indicated in Table 5, and consistent with previously presented data (Manios et al. 2002), there were notable differences in the extent to which the nutrient intake changed in the two groups during the 6-year intervention period. More specifically, the increases over this period in the average total fat, saturated fat, monounsaturated fat and protein intake were significantly higher in the CG than in the IG $(P<0.05)$. Nonetheless, there

Table 1. Baseline measurements obtained from pupils who dropped out or were lost to follow-up and those with complete participation in all three examinations

\begin{tabular}{|c|c|c|c|c|c|}
\hline & \multicolumn{2}{|c|}{$\begin{array}{l}\text { Pupils who dropped-out or } \\
\text { were lost to follow-up }\end{array}$} & \multicolumn{2}{|c|}{$\begin{array}{l}\text { Pupils participating in all three } \\
\text { examinations }\end{array}$} & \multirow[b]{2}{*}{$P$} \\
\hline & Mean & SE & Mean & SE & \\
\hline Anthropometric indices & & $(n 298)$ & & $(n 483)$ & \\
\hline Weight $(\mathrm{kg})$ & $23 \cdot 8$ & 4.97 & 23.5 & 4.50 & 0.398 \\
\hline Height (cm) & $119 \cdot 9$ & $5 \cdot 29$ & 120 & $5 \cdot 85$ & 0.931 \\
\hline BMI $\left(\mathrm{kg} / \mathrm{m}^{2}\right)$ & $16 \cdot 5$ & $2 \cdot 67$ & $16 \cdot 2$ & $2 \cdot 17$ & 0.209 \\
\hline Biochemical indices & & $(n 275)$ & & $(n 441)$ & \\
\hline Total cholesterol (mg/dl) & $183 \cdot 8$ & $2 \cdot 12$ & $182 \cdot 2$ & 1.44 & 0.458 \\
\hline HDL-cholesterol (mg/dl) & $58 \cdot 6$ & 0.91 & $60 \cdot 1$ & 0.66 & 0.166 \\
\hline LDL-cholesterol (mg/dl) & $113 \cdot 8$ & 2.03 & $111 \cdot 2$ & 1.39 & 0.285 \\
\hline Triacylglycerols (mg/dl) & $58 \cdot 7$ & 2.03 & 52.9 & 0.99 & 0.004 \\
\hline Fitness & & $(n 358)$ & & $(n 323)$ & \\
\hline Endurance run test (number of stages) & $1 \cdot 73$ & 0.04 & $1 \cdot 8$ & 0.05 & 0.053 \\
\hline Dietary indices & & $(n 76)$ & & $(n 136)$ & \\
\hline Energy intake (kJ/d) & $7502 \cdot 7$ & $226 \cdot 6$ & $7724 \cdot 6$ & 151.9 & 0.408 \\
\hline Total fat intake $(\mathrm{g} / \mathrm{d})$ & $84 \cdot 1$ & $2 \cdot 82$ & $87 \cdot 1$ & 2.05 & 0.393 \\
\hline Saturated fat intake $(\mathrm{g} / \mathrm{d})$ & $30 \cdot 5$ & $1 \cdot 21$ & $30 \cdot 8$ & 0.74 & 0.814 \\
\hline Monounsaturated fat intake (g/d) & $34 \cdot 6$ & $1 \cdot 23$ & $36 \cdot 8$ & 1.04 & $0 \cdot 226$ \\
\hline Polyunsaturated fat intake (g/d) & $9 \cdot 72$ & 0.55 & $9 \cdot 58$ & 0.26 & 0.804 \\
\hline Protein intake $(\mathrm{g} / \mathrm{d})$ & $62 \cdot 4$ & $2 \cdot 19$ & $62 \cdot 9$ & 1.55 & 0.864 \\
\hline Carbohydrate intake (g/d) & $195 \cdot 2$ & $6 \cdot 88$ & $202 \cdot 8$ & 4.55 & 0.360 \\
\hline Physical activity ${ }^{*}$ & Median & $\begin{array}{l}\text { 25-75th percentile } \\
(n 254)\end{array}$ & Median & $\begin{array}{l}\text { 25-75th percentile } \\
(n 425)\end{array}$ & \\
\hline Moderate-to-vigorous physical activity (min/week) & 0.0 & $0.0-120.0$ & 0.0 & $0.0-60.0$ & $0 \cdot 264$ \\
\hline
\end{tabular}

${ }^{*}$ In the case of physical activity, the level of significance was assessed with the non-parametric Mann-Whitney test. 
Table 2. Changes in BMI and serum lipids for the intervention ( $n$ 250) and control $(n$ 191) group following the 6-year intervention and at the 4-year post-intervention follow-up (10 years from baseline)*

\begin{tabular}{|c|c|c|c|c|c|c|c|c|c|c|c|c|}
\hline \multirow[b]{2}{*}{ Serum lipids } & \multicolumn{2}{|c|}{ Baseline (1992) } & \multicolumn{2}{|c|}{$\begin{array}{l}\text { End of interven- } \\
\text { tion (1998) }\end{array}$} & \multicolumn{2}{|c|}{ 6-year change } & \multirow[b]{2}{*}{$P$} & \multicolumn{2}{|c|}{ Follow-up (2002) } & \multicolumn{2}{|c|}{ 10-year change } & \multirow[b]{2}{*}{$P$} \\
\hline & Mean & SE & Mean & SE & Mean & SE & & Mean & SE & Mean & SE & \\
\hline \multicolumn{13}{|c|}{ Total cholesterol (mg/dl) } \\
\hline Control group & 174.5 & $2 \cdot 19$ & 173.4 & $2 \cdot 05$ & -1.02 & 1.88 & \multirow[t]{2}{*}{0.013} & $164 \cdot 8$ & 1.96 & $-9 \cdot 70$ & 2.03 & \multirow[t]{2}{*}{0.001} \\
\hline Intervention group & $187 \cdot 8$ & 1.96 & $174 \cdot 3$ & 1.94 & -13.6 & 1.50 & & 163.5 & 1.92 & $-24 \cdot 3$ & 1.65 & \\
\hline \multicolumn{13}{|c|}{ LDL-cholesterol (mg/dl) } \\
\hline Control group & $104 \cdot 2$ & $2 \cdot 10$ & $103 \cdot 3$ & 1.73 & -0.87 & 1.65 & \multirow[t]{2}{*}{$<0.001$} & $101 \cdot 7$ & 1.60 & -2.49 & 1.75 & \multirow[t]{2}{*}{$<0.001$} \\
\hline Intervention group & 117.0 & 1.84 & 103.5 & 1.82 & -13.5 & 1.40 & & 98.3 & 1.64 & $-18 \cdot 6$ & 1.41 & \\
\hline \multicolumn{13}{|c|}{ HDL-cholesterol (mg/dl) } \\
\hline Control group & $59 \cdot 6$ & $1 \cdot 11$ & $56 \cdot 4$ & 1.09 & -3.21 & 1.09 & \multirow[t]{2}{*}{$0 \cdot 132$} & 50.0 & 0.83 & $-9 \cdot 60$ & $1 \cdot 10$ & \multirow[t]{2}{*}{0.014} \\
\hline Intervention group & $60 \cdot 3$ & 0.79 & 57.5 & 0.98 & -2.82 & 0.97 & & $52 \cdot 0$ & 0.77 & -8.34 & 0.75 & \\
\hline \multicolumn{13}{|c|}{ Total cholesterol : HDL-cholesterol } \\
\hline Control group & $3 \cdot 10$ & 0.07 & $3 \cdot 24$ & 0.06 & 0.14 & 0.06 & \multirow[t]{2}{*}{0.049} & 3.41 & 0.05 & 0.31 & 0.06 & \multirow[t]{2}{*}{0.001} \\
\hline Intervention group & 3.23 & 0.05 & $3 \cdot 18$ & 0.07 & -0.05 & 0.07 & & $3 \cdot 27$ & 0.05 & 0.04 & 0.05 & \\
\hline \multicolumn{13}{|c|}{ Triacylglycerols (mg/dl) } \\
\hline Control group & $53 \cdot 3$ & 1.59 & $68 \cdot 6$ & 1.69 & $15 \cdot 3$ & 1.96 & \multirow[t]{2}{*}{0.575} & $65 \cdot 1$ & 2.00 & $11 \cdot 8$ & $2 \cdot 19$ & \multirow[t]{2}{*}{0.474} \\
\hline Intervention group & $52 \cdot 9$ & 1.33 & $66 \cdot 8$ & $1 \cdot 77$ & $13 \cdot 9$ & $1 \cdot 79$ & & $65 \cdot 6$ & $1 \cdot 80$ & $12 \cdot 7$ & 1.83 & \\
\hline
\end{tabular}

* The differences between the two groups were evaluated using linear mixed models analysis. Adjustments were made for baseline values, gender and parental education. School was taken as a random effect. Values presented are for those pupils with complete biochemical data in 1992, 1998 and 2002.

were no significant differences between the IG and CG pupils regarding the changes in energy and nutrients intake during the 10 -year period from baseline to the post-intervention follow-up examination.

Table 3. Results from stepwise multiple linear regression analysis with the 10 -year change in serum lipids concentration as the dependent variables

\begin{tabular}{|c|c|c|c|c|}
\hline \multirow[b]{2}{*}{ Dependent variable } & \multicolumn{2}{|c|}{ Model $1^{*}$} & \multicolumn{2}{|c|}{ Model 2† } \\
\hline & $\beta_{1}$ & $P$ & $\beta_{2}$ & $P$ \\
\hline$\Delta$ Total cholesterol $(\mathrm{mg} / \mathrm{dl})$ & \multicolumn{2}{|c|}{ Adjusted $R^{2}: 0.09$} & \multicolumn{2}{|c|}{ Adjusted $R^{2}: 0 \cdot 18$} \\
\hline Intervention v.control group & -0.28 & $<0.001$ & -0.32 & 0.010 \\
\hline $\begin{array}{l}\Delta \text { Moderate-to-vigorous } \\
\text { physical activity }\end{array}$ & -0.12 & 0.027 & $-0 \cdot 12$ & 0.304 \\
\hline$\Delta$ Endurance run test score & & & -0.26 & 0.032 \\
\hline$\Delta$ LDL-cholesterol (mg/dl) & \multicolumn{2}{|c|}{ Adjusted $R^{2}: 0.15$} & \multicolumn{2}{|c|}{ Adjusted $R^{2}: 0.49$} \\
\hline $\begin{array}{l}\text { Intervention } v \text {. control } \\
\text { group }\end{array}$ & -0.37 & $<0.001$ & -0.49 & $<0.001$ \\
\hline$\Delta \mathrm{BMI}$ & $1 \cdot 82$ & 0.048 & 0.09 & 0.397 \\
\hline $\begin{array}{l}\Delta \text { Total cholesterol: } \\
\text { HDL-cholesterol }\end{array}$ & \multicolumn{2}{|c|}{ Adjusted $R^{2}: 0 \cdot 10$} & \multicolumn{2}{|c|}{ Adjusted $R^{2}: 0.27$} \\
\hline $\begin{array}{l}\text { Intervention } v \text {. control } \\
\text { group }\end{array}$ & $-0 \cdot 16$ & 0.004 & -0.27 & 0.025 \\
\hline$\Delta \mathrm{BMI}$ & $0 \cdot 27$ & $<0.001$ & 0.35 & 0.004 \\
\hline $\begin{array}{l}\Delta \text { Moderate-to-vigorous } \\
\text { physical activity }\end{array}$ & -0.28 & 0.038 & -0.24 & 0.047 \\
\hline$\Delta$ Triacylglycerols $(\mathrm{mg} / \mathrm{dl})$ & \multicolumn{2}{|c|}{ Adjusted $R^{2}: 0.06$} & \multicolumn{2}{|c|}{ Adjusted $R^{2}: 0.07$} \\
\hline $\begin{array}{l}\Delta \text { Moderate-to-vigorous } \\
\text { physical activity }\end{array}$ & -0.15 & 0.005 & -0.09 & 0.473 \\
\hline$\Delta \mathrm{BMl}$ & 0.23 & $<0.001$ & 0.09 & 0.474 \\
\hline$\Delta$ Endurance run test score & & & -0.27 & 0.038 \\
\hline
\end{tabular}

$\beta$, standardized beta coefficient; $\Delta$, the change observed for the specific variable over the 10 -year period of follow-up re-examination.

* Model 1 was conducted for 425 subjects. Independent variables in the model: 0 , control/1, intervention (dummy variable), parental educational level and 10-year change in BMI and moderate-to-vigorous physical activity.

t Model 2 was conducted for 132 subjects. Independent variables in the model: 0 , control/1, intervention (dummy variable), parental educational level and 10-year change in BMI, endurance run test, moderate-to-vigorous physical activity, saturated fat intake, monounsaturated fat intake, polyunsaturated fat intake, carbohydrate intake and protein intake.

\section{Discussion}

The 10-year follow-up of the Cretan Health and Nutrition Education Programme revealed that the favourable changes observed for serum lipids in the IG compared with the $\mathrm{CG}$, at the end of the intervention period, were also present 4 years after the programme's cessation. The maintenance of favourable changes in serum lipid concentrations for the IG subjects could be mainly attributed to their higher physical activity levels and their lower BMI values, compared with the CG pupils, over the follow-up examination period. This observation is supported by the results derived from model 1 of the multiple linear regression analysis (Table 3), indicating a significant positive effect of participation in the intervention on the changes observed in TC, LDL-C and TC:HDL-C ratio, as well as a negative correlation of these changes with the respective changes observed for leisure-time MVPA and a positive one with the changes in BMI. When the analysis was repeated including fitness and dietary indices in the regression (model 2 in Table 3), many of the aforementioned associations lost their statistical significance, although participation in the intervention remained significant for all variables excluding TG.

The different findings observed with model 2 could be due to the smaller number of subjects which we approximately one third of those included in model 1. Additionally, the significant changes observed for TC and LDL-C over the 10-year followup could also be attributed to the unfavourably high levels of these indices obtained for both groups at baseline, leaving space for significant improvement (Lytle et al. 2002; Manios et al. 2002). This was even more pronounced for the IG, although the sampling procedures followed at baseline aimed to ensure the representativeness and homogeneity of the two groups. Both the unfavourably high levels of the biochemical indices at baseline as well as the differences observed between the two groups for these indices should be kept in mind when interpreting the effectiveness of the current intervention programme, as discussed extensively in previous publications (Manios et al. 1999, 2002; Lytle et al. 2002). 
The existing body of scientific evidence presented in the recent literature highlights the undeniable role of physical activity as an important determinant of certain lipid metabolic adaptations (Hardman, 1999; Durstine et al. 2001; Bouziotas et al. 2004). The activities of the lipid metabolism enzymes lipoprotein lipase, lecithin cholesterol acyltransferase and hepatic lipase seem to increase in parallel with increases in physical activity level (Superko, 1991; Durstine et al. 2001), providing some possible explanations for the findings of the current study. In addition, the positive effect of regular exercise on controlling the concentration of blood lipids could be through weight management as several weight-reduction trials have consistently reported better results when physical activity is included in the treatment protocol (Williams et al. 2002).

Indeed, the favourable changes observed in leisure-time MVPA and BMI for the IG pupils at the end of the 6-year intervention period (Manios et al. 1998a, 2002; Manios \& Kafatos, 1999) were partially sustained at the post-intervention examination (Table 4). The data from the current study showed that IG pupils were motivated to continue engaging in MVPA, whereas the MVPA levels of the CG pupils were decreased by $13.2 \mathrm{~min} /$ week from baseline to the post-intervention follow-up. However, both IG and CG pupils showed a decline in the mean time devoted to MVPA from age 12 to age 16 .

This decline in leisure-time MVPA during this life stage is a common finding in many developed countries (Caspersen et al. 2000). Physical activity during adolescence diminishes for a variety of reasons. Adolescents tend to walk or bicycle less and increasingly rely on cars for transportation. Furthermore, a trend away from an active lifestyle and any kind of recreational physical activity is evident, and the reliance on sedentary entertainment, including television, video games and computers, has increased. Although this is true for both sexes, it seems to be more pronounced among girls (Kimm et al. 2000). This observation seems to lie in social and cultural beliefs regarding the types of activity appropriate for boys and girls. According to recent evidence, family and society appear to influence the level and type of physical activity that girls are engaged in and may therefore determine their lifetime habits with respect to habitual physical activity (Vilhjalmsson \& Kristjansdottir, 2003).
The current finding regarding the smaller decline in leisure-time MVPA by the IG pupils suggests that the effects of intervention were generalized outside the supervised exercise setting and raises the encouraging possibility that the project's effects last beyond the end of the intervention period. Indeed, one of the dominant goals of the programme was to increase the time devoted to MVPA during the physical education classes with activities that were pleasant, non-competitive and cooperative, fostering a greater enjoyment and a sense of mastery for the children (Manios et al. 1998a). Furthermore, this approach, combined with parental encouragement to support the children in increasing their physical activity out of school, was an essential parameter of the programme, contributing to maintaining some levels of leisure-time MVPA across this life stage (van Beurden et al. 2003).

Only a very few studies have so far included a post-intervention follow-up reassessment of physical activity maintenance. The longest follow-ups were 12,7 and 3 years, respectively, for the Oslo Youth Study, Class of 89 and CATCH study (Kelder et al. 1993; Klepp et al. 1994; Nader et al. 1999). The findings of these previous studies, regardless of the method used to assess physical activity, are in line with those of the current study, showing respective declines during adolescence but still reporting significant increases in physical activity in IG $v$. CG subjects. More specifically, according to data from the CATCH study, the IG pupils had significantly higher levels of physical activity than CG pupils 3 years after the programme ended (Nader et al. 1999). Similar findings applied to the former IG subjects of the Class of 89 and Oslo Youth Study, who remained more active some years after the end of the intervention compared with the former CG (Kelder et al. 1993; Klepp et al. 1994).

Although the current study has indicated significant favourable changes in nutrient intake for the IG compared with the CG pupils at the end of the 6-year intervention period (Manios et al. 2002), no such differences were present at the 10-year follow-up (Table 5). The favourable changes observed for the IG at the end of the intervention could be attributed to the intervention approach used by the current school-based intervention programme. Emphasis was laid not only on the adoption of nutrition messages for different school grades, but also on encouraging

Table 4. Changes in BMI, leisure-time physical activity and fitness for the intervention and control group following the 6-year intervention and the 4-year postintervention follow-up (10 years from baseline) ${ }^{*}$

\begin{tabular}{|c|c|c|c|c|c|c|c|c|c|c|c|c|}
\hline & \multicolumn{12}{|c|}{ All subjects } \\
\hline & \multicolumn{2}{|c|}{ Baseline (1992) } & \multicolumn{2}{|c|}{$\begin{array}{l}\text { End of interven- } \\
\text { tion (1998) }\end{array}$} & \multicolumn{2}{|c|}{ 6-year change } & \multirow[b]{2}{*}{$P$} & \multicolumn{2}{|c|}{$\begin{array}{l}\text { Follow-up } \\
\text { (2002) }\end{array}$} & \multicolumn{2}{|c|}{ 10-year change } & \multirow[b]{2}{*}{$P$} \\
\hline & Mean & SE & Mean & SE & Mean & SE & & Mean & SE & Mean & SE & \\
\hline \multicolumn{13}{|l|}{ BMI $\left(\mathrm{kg} / \mathrm{m}^{2}\right)$} \\
\hline Control group ( $n$ 222) & $16 \cdot 3$ & $0 \cdot 15$ & $20 \cdot 3$ & 0.26 & 4.03 & 0.17 & 0.043 & $23 \cdot 0$ & 0.29 & $6 \cdot 67$ & 0.21 & 0.014 \\
\hline \multicolumn{13}{|c|}{ Moderate-to-vigorous physical activity (min/week) } \\
\hline Control group ( $n$ 187) & 74.4 & 11.4 & $273 \cdot 0$ & $27 \cdot 3$ & $198 \cdot 6$ & $28 \cdot 3$ & 0.030 & $61 \cdot 2$ & $6 \cdot 87$ & $-13 \cdot 2$ & $10 \cdot 9$ & 0.038 \\
\hline Intervention group ( $n$ 238) & $50 \cdot 0$ & $8 \cdot 78$ & $365 \cdot 2$ & 29.9 & $315 \cdot 2$ & $30 \cdot 8$ & & $88 \cdot 3$ & 8.04 & $38 \cdot 3$ & $11 \cdot 7$ & \\
\hline \multicolumn{13}{|c|}{ Endurance run test (number of stages) } \\
\hline Control group ( $n$ 167) & 1.84 & 0.07 & 3.07 & $0 \cdot 12$ & $1 \cdot 23$ & 0.11 & $<0.001$ & 3.88 & 0.17 & $2 \cdot 04$ & $0 \cdot 16$ & 0.169 \\
\hline Intervention group ( $n$ 156) & 1.75 & 0.07 & 4.59 & 0.17 & $2 \cdot 83$ & 0.15 & & $4 \cdot 15$ & 0.17 & 2.39 & 0.17 & \\
\hline
\end{tabular}

* The differences between the two groups were evaluated using linear mixed models analysis. Adjustments were made for baseline values, gender and parental education. School was taken as a random effect. Values are presented for those pupils with complete BMI, physical activity and fitness data in 1992, 1998 and 2002. 
Table 5. Changes in daily energy and nutrient intake for the intervention ( $n 70)$ and control group ( $n$ 66) following the 6-year intervention and the 4-year post-intervention follow-up (10 years from baseline)*

\begin{tabular}{|c|c|c|c|c|c|c|c|c|c|c|c|c|}
\hline & \multicolumn{2}{|c|}{ Baseline (1992) } & \multicolumn{2}{|c|}{$\begin{array}{l}\text { End of interven- } \\
\text { tion (1998) }\end{array}$} & \multicolumn{2}{|c|}{ 6-year change } & \multirow[b]{2}{*}{$P$} & \multicolumn{2}{|c|}{ Follow-up (2002) } & \multicolumn{2}{|c|}{ 10-year change } & \multirow[b]{2}{*}{$P$} \\
\hline & Mean & SE & Mean & SE & Mean & SE & & Mean & SE & Mean & SE & \\
\hline \multicolumn{13}{|l|}{ Energy intake $(\mathrm{kJ} / \mathrm{d})$} \\
\hline Control group & $7602 \cdot 8$ & $209 \cdot 1$ & $8866 \cdot 0$ & $280 \cdot 3$ & $1263 \cdot 3$ & 318.9 & 0.092 & 8848.9 & $412 \cdot 7$ & $1246 \cdot 1$ & $450 \cdot 4$ & 0.322 \\
\hline Intervention group & $7728 \cdot 4$ & $239 \cdot 7$ & $8423 \cdot 2$ & $264 \cdot 0$ & $694 \cdot 7$ & 284.9 & & $9700 \cdot 3$ & $467 \cdot 6$ & 1971.8 & 494.4 & \\
\hline \multicolumn{13}{|l|}{ Total fat intake $(\mathrm{g} / \mathrm{d})$} \\
\hline Intervention group & 86.5 & 3.05 & $92 \cdot 1$ & 3.78 & $5 \cdot 66$ & $4 \cdot 11$ & & $106 \cdot 0$ & $5 \cdot 72$ & $19 \cdot 5$ & $5 \cdot 82$ & \\
\hline \multicolumn{13}{|c|}{ Saturated fat intake $(\mathrm{g} / \mathrm{d})$} \\
\hline Control group & $30 \cdot 1$ & 1.09 & $34 \cdot 7$ & $1 \cdot 27$ & 4.59 & 1.52 & 0.022 & 33.4 & $2 \cdot 06$ & $3 \cdot 25$ & $2 \cdot 33$ & 0.449 \\
\hline Intervention group & $31 \cdot 0$ & $1 \cdot 10$ & $31 \cdot 4$ & 1.31 & 0.32 & 1.45 & & $36 \cdot 7$ & $2 \cdot 14$ & $5 \cdot 71$ & $2 \cdot 23$ & \\
\hline \multicolumn{13}{|c|}{ Monounsaturated fatty acid intake $(\mathrm{g} / \mathrm{d})$} \\
\hline Control group & $36 \cdot 4$ & 1.53 & $44 \cdot 4$ & 1.94 & 7.98 & $2 \cdot 12$ & 0.024 & $39 \cdot 2$ & $2 \cdot 47$ & $2 \cdot 76$ & $2 \cdot 82$ & 0.267 \\
\hline Intervention group & $36 \cdot 0$ & 1.48 & $39 \cdot 1$ & 1.90 & $3 \cdot 12$ & $2 \cdot 13$ & & $44 \cdot 1$ & $2 \cdot 63$ & $8 \cdot 13$ & $2 \cdot 65$ & \\
\hline \multicolumn{13}{|c|}{ Polyunsaturated fatty acid intake $(\mathrm{g} / \mathrm{d})$} \\
\hline \multicolumn{13}{|l|}{ Protein intake $(\mathrm{g} / \mathrm{d})$} \\
\hline Control group & $63 \cdot 0$ & $2 \cdot 26$ & $76 \cdot 7$ & $2 \cdot 48$ & $13 \cdot 7$ & $3 \cdot 19$ & 0.047 & $71 \cdot 2$ & 4.09 & $8 \cdot 30$ & 4.43 & 0.650 \\
\hline Intervention group & $62 \cdot 2$ & $2 \cdot 32$ & $71 \cdot 2$ & $2 \cdot 66$ & 9.02 & $2 \cdot 97$ & & $75 \cdot 1$ & 3.90 & $12 \cdot 9$ & 4.53 & \\
\hline \multicolumn{13}{|c|}{ Carbohydrate intake $(\mathrm{g} / \mathrm{d})$} \\
\hline Control group & $196 \cdot 1$ & 5.77 & $233 \cdot 1$ & $7 \cdot 14$ & $36 \cdot 9$ & 8.45 & 0.311 & $242 \cdot 3$ & $11 \cdot 5$ & $45 \cdot 9$ & $12 \cdot 4$ & 0.272 \\
\hline Intervention group & $206 \cdot 7$ & $7 \cdot 77$ & $229 \cdot 4$ & $7 \cdot 81$ & $22 \cdot 7$ & 8.97 & & $269 \cdot 1$ & $14 \cdot 1$ & $62 \cdot 5$ & $15 \cdot 6$ & \\
\hline
\end{tabular}

* Nutrient intakes were assessed in a $30 \%$ subsample. The differences between the two groups were evaluated using linear mixed models analysis. Adjustments were made for baseline values, gender and parental education. School was taken as a random effect. Values are presented for those pupils with complete dietary intake data in 1992,1998 and 2002.

total class participation and learning through experience. Most importantly, however, developing and promoting a supportive environment within schools and family, thus assisting children to adopt and maintain appropriate food choices, was central to the programme (Manios et al. 2002).

These two components, school and family environment, seem crucial in determining food intake during the pre-adolescent life span. At the follow-up examination, however, both the IG and the CG pupils were aged 16. It could be hypothesized that the parameters primarily determining their food preferences and dietary intake were probably different from those at the end of the intervention period, when they were 12 . The time between the ages of 12 and 16 years is considered a transition period. Adolescents begin to experience a need for autonomy as well as peer approval. These seemingly conflicting urges tend to result in a shift from parental and teacher influence to peer and media influence upon behaviour. As image and social needs become more important in decision-making, cultural messages become more valued. The act of eating may shift in meaning from a nutritional event to a social event, while food choices may become signs of friendship or symbols of independence. Adolescents take increasing control of what, when and where they eat and typically consume a greater proportion of their total intake outside the home, usually in convenience stores and fast-food restaurants, where pupils of this age often socialize. These parameters could possibly explain the poor maintenance of beneficial dietary patterns of the IG after the end of the intervention programme (Copeland \& Hess, 1995).

A limitation of the current study could be the participation rate at the follow-up examination, which was $61 \%$ of the original cohort. The primary reason explaining the loss of subjects through the follow-up re-examination period was the transition phase from primary to high school. As the current programme was a school-based one, those children who moved to different locations could not be tracked. Nonetheless, those children re-examined at follow-up (10th grade) comprised a representative sample of those participating in the sixth-year examination (6th grade), as no significant differences in baseline serum lipids or other health indices were detected between those examined in all three examinations and those not re-examined at follow-up, with the sole exception of TG (Table 1).

Another shortcoming of the current study was the dissociation between the changes observed for leisure-time MVPA and ERT score, especially during the post-intervention period (Table 4). This could, however, probably be attributed to the smaller set of data available on the fitness test, making the changes observed in this index not directly comparable with those obtained for the MVPA. Another interpretation of this dissociation could be the discontinuation reported by recent studies for physical activity and fitness indices from childhood through adolescence. This has been attributed to the strong genetic and physiological component of cardiorespiratory fitness compared with the large behavioural component of physical activity (Janz et al. 2000; McMurray et al. 2003).

Although the effectiveness of any intervention programme can only be assessed in the long term, the maintenance of the favourable changes obtained in serum lipids during the intervention period 4 years after the end of the programme are encouraging and underline the potential of such initiatives. These positive findings should be attributed to the approach followed by the Cretan Health and Nutrition Education Programme and the cognitive and behavioural changes achieved among pupils and their families during the intervention period. More indicative of the favourable behavioural changes were those observed for leisure-time physical activity, as this was found to remain higher for the IG than the CG pupils 4 years after the programme had ceased. Future 
health and nutrition education programmes might need to consider involving neighbourhood and society, in addition to school and family, thus developing a social and physical environment that will assist behavioural changes that should be enduring rather than transitory.

\section{Acknowledgements}

This study was supported by a research grant from Kellogg Europe, the Greek Ministry of Sports and the Greek Ministry of Education. We would also like to acknowledge the help of Irene Kafatos. The Preventive Medicine and Nutrition Clinic Research Team include: Ioanna Apostolaki, Froso Bervanaki, Sofia Flouri, Christos Hatzis, Michalis Kiriakakis, Manolis Linardakis, Irini Markatji, Katerina Sarri and George Tsimbinos.

\section{References}

Boreham C, Robson PJ, Gallagher AM, Cran GW, Savage JM \& Murray LJ (2004) Tracking of physical activity, fitness, body composition and diet from adolescence to young adulthood: the Young Hearts Project, Northern Ireland. Int J Behav Nutr Phys Act 1, 14.

Bouziotas C, Koutedakis Y, Nevill A, Ageli E, Tsigilis N, Nikolaou A \& Nakou A (2004) Greek adolescents, fitness, fatness, fat intake, activity, and coronary heart disease risk. Arch Dis Child 89, 41-44.

Caspersen CJ, Pereira MA \& Curran KM (2000) Changes in physical activity patterns in the United States, by sex and cross-sectional age. Med Sci Sports Exerc 32, 1601-1609.

Cohen MS (2004) Fetal and childhood onset of adult cardiovascular diseases. Pediatr Clin N Am 51, 1697-1719.

Committee of Experts on Sports Research (1988) EUROFIT. Rome: Edigraf Editoriale Grafica.

Copeland E \& Hess R (1995) Differences in young adolescents' coping strategies based on gender and ethnicity. J Early Adolesc 15, 203-219.

Durstine JL, Grandjean PW, Davis PG, Ferguson MA, Alderson NL \& DuBose KD (2001) Blood lipid and lipoprotein adaptations to exercise: a quantitative analysis. Sports Med 31, 1033-1062.

Friedewald WT, Levy RI \& Fredrickson DS (1972) Estimation of the concentration of low-density lipoprotein cholesterol in plasma, without use of the preparative ultracentrifuge. Clin Chem 18, 499-502.

Hardman AE (1999) Physical activity intervention studies with healthrelated outcomes: some issues. J Sports Sci 17, 685-687.

Harrell JS, Gansky SA, McMurray RG, Bangdiwala SI, Frauman AC \& Bradley CB (1998) School-based interventions improve heart health in children with multiple cardiovascular disease risk factors. Pediatrics 102, $371-380$.

Hayman LL, Williams CL, Daniels SR, Steinberger J, Paridon S, Dennison BA \& McCrindle BW (2004) Cardiovascular health promotion in the schools: a statement for health and education professionals and child health advocates from the Committee on Atherosclerosis, Hypertension, and Obesity in Youth (AHOY) of the Council on Cardiovascular Disease in the Young, American Heart Association. Circulation 110, 2266-2275.

Janz KF, Dawson JD \& Mahoney LT (2000) Tracking physical fitness and physical activity from childhood to adolescence: the muscatine study. Med Sci Sports Exerc 32, 1250-1257.

Kafatos A, Manios Y, Markatji I, Giachetti I, Vaz de Almeida MD \& Engstrom LM (1999) Regional, demographic and national influences on attitudes and beliefs with regard to physical activity, body weight and health in a nationally representative sample in the European Union. Public Health Nutr 2, 87-95.

Kafatos A \& Papoutsakis G (1998) Mortality rates in Greece and their relationship to the Mediterranean diet and to health and nutrition education. Iatriki 73, 287-301.
Kelder SH, Mitchell PD, McKenzie TL, Derby C, Strikmiller PK, Luepker RV \& Stone EJ (2003) Long-term implementation of the CATCH physical education program. Health Educ Behav 30, 463-475.

Kelder SH, Perry CL \& Klepp KI (1993) Community-wide youth exercise promotion: long-term outcomes of the Minnesota Heart Health Program and the Class of 1989 Study. J Sch Health 63, 218-223.

Kimm SY, Glynn NW, Kriska AM, Fitzgerald SL, Aaron DJ, Similo SL, McMahon RP \& Barton BA (2000) Longitudinal changes in physical activity in a biracial cohort during adolescence. Med Sci Sports Exerc 32, 1445-1454.

Klepp KL, Oygard L, Tell GS \& Vellar OD (1994) Twelve year follow-up study of a school-based health education program. Eur J Public Health 4, 195-200.

Law M (2000) Dietary fat and adult diseases and the implications for childhood nutrition: an epidemiologic approach. Am J Clin Nutr 72, 1291S-1296S.

Lee IM, Sesso HD \& Paffenbarger RS Jr (2000) Physical activity and coronary heart disease risk in men: does the duration of exercise episodes predict risk? Circulation 102, 981-986.

Li S, Chen W, Srinivasan SR, Bond MG, Tang R, Urbina EM \& Berenson GS (2003) Childhood cardiovascular risk factors and carotid vascular changes in adulthood: the Bogalusa Heart Study. J Am Med Assoc 290, 2271-2276.

Luepker RV, Perry CL, McKinlay SM, et al. (1996) Outcomes of a field trial to improve children's dietary patterns and physical activity. The Child and Adolescent Trial for Cardiovascular Health. CATCH collaborative group. J Am Med Assoc 275, 768-776.

Lytle LA, Jacobs DR Jr, Perry CL \& Klepp KI (2002) Achieving physiological change in school-based intervention trials: what makes a preventive intervention successful? Br J Nutr 88, 219-221.

Manios Y \& Kafatos A (1999) Health and nutrition education in elementary schools: changes in health knowledge, nutrient intakes and physical activity over a six year period. Public Health Nutr 2, 445-448.

Manios Y, Kafatos A \& Mamalakis G (1998a) The effects of a health education intervention initiated at first grade over a 3 year period: physical activity and fitness indices. Health Educ Res 13, 593-606.

Manios Y, Kafatos A \& Markakis G (1998b) Physical activity in 6-year-old children: validation of two proxy reports. Pediatr Exerc Sci 10, 176-188.

Manios Y, Moschandreas J, Hatzis C \& Kafatos A (1999) Evaluation of a health and nutrition education program in primary school children of Crete over a three-year period. Prev Med 28, 149-159.

Manios Y, Moschandreas J, Hatzis C \& Kafatos A (2002) Health and nutrition education in primary schools of Crete: changes in chronic disease risk factors following a 6-year intervention programme. $\mathrm{Br} \mathrm{J} \mathrm{Nutr}$ 88, 315-324.

McKenzie TL, Li D, Derby CA, Webber LS, Luepker RV \& Cribb P (2003) Maintenance of effects of the CATCH physical education program: results from the CATCH-ON study. Health Educ Behav 30, 447-462.

McMurray RG, Harrell JS, Bangdiwala SI \& Hu J (2003) Tracking of physical activity and aerobic power from childhood through adolescence. Med Sci Sports Exerc 35, 1914-1922.

Mikkila V, Rasanen L, Raitakari OT, Pietinen P \& Viikari J (2004) Longitudinal changes in diet from childhood into adulthood with respect to risk of cardiovascular diseases: the Cardiovascular Risk in Young Finns Study. Eur J Clin Nutr 58, 1038-1045.

Nader PR, Stone EJ, Lytle LA, et al. (1999) Three-year maintenance of improved diet and physical activity: the $\mathrm{CATCH}$ cohort. Child and Adolescent Trial for Cardiovascular Health. Arch Pediatr Adolesc Med 153, 695-704.

Osganian SK, Hoelscher DM, Zive M, Mitchell PD, Snyder P \& Webber LS (2003) Maintenance of effects of the eat smart school food service program: results from the CATCH-ON study. Health Educ Behav 30, 418-433.

Pitsavos C, Panagiotakos DB, Chrysohoou C, Skoumas J, Papaioannou I, Stefanadis C \& Toutouzas PK (2002) The effect of Mediterranean diet on the risk of the development of acute coronary syndromes in 
hypercholesterolemic people: a case-control study (CARDIO2000) Coron Artery Dis 13, 295-300.

Pitsavos C, Panagiotakos DB, Chrysohoou C \& Stefanadis C (2003) Epidemiology of cardiovascular risk factors in Greece: aims, design and baseline characteristics of the ATTICA study. BMC Public Health 3, 32 .

Raitakari OT, Juonala M, Kahonen M, et al. (2003) Cardiovascular risk factors in childhood and carotid artery intima-media thickness in adulthood: the Cardiovascular Risk in Young Finns Study. J Am Med Assoc 290, 2277-2283.

Sesso HD, Paffenbarger RS Jr \& Lee IM (2000) Physical activity and coronary heart disease in men: The Harvard Alumni Health Study. Circulation 102, 975-980.

Superko HR (1991) Exercise training, serum lipids, and lipoprotein particles: is there a change threshold? Med Sci Sports Exerc 23, 677-685.

van Beurden E, Barnett LM, Zask A, Dietrich UC, Brooks LO \& Beard J (2003) Can we skill and activate children through primary school physical education lessons? "Move it Groove it" - a collaborative health promotion intervention. Prev Med 36, 493-501.
Vilhjalmsson R \& Kristjansdottir G (2003) Gender differences in physical activity in older children and adolescents: the central role of organized sport. Soc Sci Med 56, 363-374.

Walter HJ \& Wynder EL (1989) The development, implementation, evaluation, and future directions of a chronic disease prevention program for children: the "Know Your Body" studies. Prev Med 18, 59-71.

Wei M, Kampert JB, Barlow CE, Nichaman MZ, Gibbons LW, Paffenbarger RS Jr \& Blair SN (1999) Relationship between low cardiorespiratory fitness and mortality in normal-weight, overweight, and obese men. J Am Med Assoc 282, 1547-1553.

Williams CL, Arnold CB \& Wynder EL (1977) Primary prevention of chronic disease beginning in childhood. The "know your body" program: design of study. Prev Med 6, 344-357.

Williams CL, Hayman LL, Daniels SR, Robinson TN, Steinberger J, Paridon S \& Bazzarre T (2002) Cardiovascular health in childhood: a statement for health professionals from the Committee on Atherosclerosis, Hypertension, and Obesity in the Young (AHOY) of the Council on Cardiovascular Disease in the Young, American Heart Association. Circulation 106, 143-160. 